\title{
C-Terminal Region of Plant Ferredoxin-Like Protein Is Required to Enhance Resistance to Bacterial Disease in Arabidopsis thaliana
}

\author{
Yi-Hsien Lin, Hsiang-En Huang, Yen-Ru Chen, Pei-Luan Liao, Ching-Lian Chen, and Teng-Yung Feng
}

First, third, fourth, fifth, and sixth authors: Institute of Plant and Microbial Biology, Academia Sinica, Nankang, Taipei, 115, Taiwan; and second author: Department of Life Science, National Taitung University, Taitung, 684, Taiwan. Accepted for publication 18 January 2011.

\section{ABSTRACT}

Lin, Y.-H., Huang, H.-E., Chen, Y.-R., Liao, P.-L., Chen, C.-L., and Feng, T.-Y. 2011. C-terminal region of plant ferredoxin-like protein is required to enhance resistance to bacterial disease in Arabidopsis thaliana. Phytopathology 101:741-749.

Protein phosphorylation is an important biological process associated with elicitor-induced defense responses in plants. In a previous report, we described how plant ferredoxin-like protein (PFLP) in transgenic plants enhances resistance to bacterial pathogens associated with the hypersensitive response (HR). PFLP possesses a putative casein kinase II phosphorylation (CK2P) site at the C-terminal in which phosphorylation occurs rapidly during defense response. However, the contribution of this site to the enhancement of disease resistance and the intensity of HR has not been clearly demonstrated. In this study, we generated two versions of truncated PFLP, PEC (extant CK2P site) and PDC (deleted CK2P site), and assessed their ability to trigger HR through harpin (HrpZ) derived from Pseudomonas syringae as well as their resistance to Ralstonia solanacearum. In an infiltration assay of HrpZ, PEC intensified harpinmediated HR; however, PDC negated this effect. Transgenic plants expressing these versions indicate that nonphosphorylated PFLP loses its ability to induce HR or enhance disease resistance against $R$. solanacearum. Interestingly, the CK2P site of PFLP is required to induce the expression of the NADPH oxidase gene, AtrbohD, which is a reactive oxygen species producing enzyme. This was further confirmed by evaluating the HR on NADPH oxidase in mutants of Arabidopsis. As a result, we have concluded that the $\mathrm{CK} 2 \mathrm{P}$ site is required for the phosphorylation of PFLP to enhance disease resistance.
Elicitor-induced defense responses enable plants to prevent or restrict the growth and proliferation of pathogens. Several sequential events are involved in the perception, induction, and expression of elicitors in the process of such defensive tactics. The production of reactive oxygen species (ROS) triggered by pathogen-associated molecular patterns is a well-known defensive strategy employed by plants to resist pathogenic infection $(10,23$, 24,26,30). ROS are responsible for hypersensitive response (HR) involving localized cell death at the site of the infection (25). Many transgenic plants use this strategy to increase resistance to plant pathogens $(16,38,40)$ through processes such as the ectopic expression of plant ferredoxin-like protein (PFLP). Our laboratory reported that PFLP in transgenic plants provides resistance against a broad spectrum of bacterial pathogens $(6,16,17$, 21,22,39).

PFLP is a leaf-type ferredoxin isolated from sweet pepper with three functional domains, including the $\mathrm{N}$-terminal signal peptide, the $2 \mathrm{Fe}-2 \mathrm{~S}$ domain, and the casein kinase II phosphorylation (CK2P) site at C-terminal (6). The functional domains of PFLP that confer disease resistance can be confirmed through replacement or truncation techniques. Previous research has shown that conferring disease resistance against bacterial pathogens requires PFLP targeting to extra-chloroplasts, indicating that PFLPmediated disease resistance depends on subcellular localization (22). The $2 \mathrm{Fe}-2 \mathrm{~S}$ domain has also shown antimicrobial activity, as reported in a previous study (15). In our previous study, an unknown harpin-activated kinase phosphorylated the CK2P site at

Corresponding author: T.-Y. Feng; E-mail address: mpmi224@gate.sinica.edu.tw

*The $e$-Xtra logo stands for "electronic extra" and indicates that Figures 4 and 5 appear in color online.

doi:10.1094/PHYTO-08-10-0220

(C) 2011 The American Phytopathological Society the C-terminal of PFLP (14). The CK2P site was phosphorylated by a casein kinase II (CK2), which phosphorylates a variety of proteins in the regulation of nuclear transport, plant development, and flowering time $(19,27,29)$. Whether the CK2 phosphorylates PFLP is still unknown, it is clear that PFLP intensifies harpinmediated HR $(6,14,16,22)$. Because $H R$ is an effective defense response during pathogenic infection (23), determining the precise means by which the CK2P site of PFLP enhances disease resistance warrants further examination.

In this study, we generated two truncated versions of PFLP to determine the importance of the CK2P site in enhancing disease resistance and discuss the possible role played by the phosphorylation of PFLP in intensifying harpin-triggered HR.

\section{MATERIALS AND METHODS}

Plants and bacteria growth conditions. Seeds of Arabidopsis thaliana ecotype Columbia were sown in sterilized peat moss, and the seedlings were transferred to individual pots for further experiments. The plants were grown in a growth chamber at $22^{\circ} \mathrm{C}$ (16 h light/8 h dark). The 5-week-old plants were used for Agrobacterium-mediated transformation. Escherichia coli DH5 $\alpha$, BL21 (DE3) and Agrobacterium tumefaciens GV3101 were grown in Luria-Bertani (LB) broth or on LB agar plates at 37 and $28^{\circ} \mathrm{C}$, respectively. Antibiotics were used in the following concentrations: kanamycin at $50 \mu \mathrm{g} / \mathrm{ml}$ for recombinant plasmids in E. coli, and gentamycin at $50 \mu \mathrm{g} / \mathrm{ml}$ for Agrobacterium tumefaciens. For pathogen inoculation, Ralstonia solanacearum $\mathrm{Rd} 15$ was cultured at $28^{\circ} \mathrm{C}$ for $48 \mathrm{~h}$ on a 2,3,5-triphenyl tetrazolium chloride (TZC) medium (18).

Preparation of recombinant proteins. To prepare recombinant proteins of PFLP and two truncated versions, PDC (CK2Pdeleted PFLP) and PEC (CK2P-extant PFLP) (Fig. 1A), three kinds of DNA fragments were amplified from the pflp gene 
(AF039662) with primers PFLP-N16F/PFLP-B16RM, PFLPN16F/PDC-B16R, and PFLP-N16F/PEC-B16R, respectively (Table 1). Three distinct DNA fragments were subcloned in an expression vector, pET16b, to generate pET-PFLP, pET-PDC, and pET-PEC, respectively. The E. coli BL21 (DE3) containing each recombinant plasmid was cultured in LB broth in the presence of $0.1 \mathrm{M}$ isopropylthio- $\beta$-D-galactoside. To produce a recombinant protein, the bacterial culture was sonicated in $25 \mathrm{mM}$ Lysis buffer (50 mM Tris- $\mathrm{HCl}, 300 \mathrm{mM} \mathrm{NaCl}, 10 \mathrm{mM}$ Imidazole, $\mathrm{pH} 7.5$ ) for $30 \mathrm{~s}$, and centrifuged at $10,000 \times g$ for $10 \mathrm{~min}$. The recombinant proteins were then purified using a Ni-NTA Spin Kit (Qiagen). Purified protein extracts of $0.5 \mu \mathrm{g}$ were fractionated into $15 \%$ sodium dodecyl sulfate-polyacrylamide gel electrophoresis (SDS-PAGE), and the separated proteins were then transferred to an Immobilon-P PVDF membrane (Millipore). This membrane was stained with Ponceau S (Sigma-Aldrich) prior to immunoblotting, and western blot was performed by using Anti$6 \mathrm{x}$-His rabbit polyclonal antiserum (1:2,000; Rockland) specific for $6 \mathrm{x}-\mathrm{His}$ tag and HRP-conjugated goat anti-rabbit immunoglobulin $\mathrm{G}$ (IgG) (1:2,000; Rockland). The immuno-signals were then colored with a metal-enhanced DAB substrate kit (Thermo Scientific).

Detection of $\mathrm{HR}$ and $\mathrm{H}_{2} \mathrm{O}_{2}$ accumulation. The preparation of protein of HrpZ was carried out according to the procedure adopted in previous research (9). The HrpZ-induced HR ratio and ROS accumulation of all of the Arabidopsis plants used in this study were determined following the protocol previously described (22). Briefly, the mature leaves were punctured with a 25-gauge needle to form tiny holes and then infiltrated with HrpZ at $0.5 \mathrm{mg} / \mathrm{ml}$ by pressing a $1-\mathrm{ml}$ blunt syringe through the holes. After treatment, plants were grown in a growth chamber for $24 \mathrm{~h}$. The HR ratio of one plant was calculated as $(\mathrm{Nn} / 6) \times 100 \%$, where $\mathrm{Nn}$ is the number of inoculation sites with necrosis and 6 is the total number of inoculation sites. For $\mathrm{H}_{2} \mathrm{O}_{2}$ observation, leaves were cut $16 \mathrm{~h}$ after treatment according to the established protocol (22) using $5 \mathrm{mM}$ of 3,3'-diaminobenzindine (DAB). Brown precipitates indicated $\mathrm{H}_{2} \mathrm{O}_{2}$ accumulation in the leaves (7).

Phosphorylation assay. The experiments in this study were designed to determine whether the CK2P site is required for the phosphorylation of PFLP in response to harpin. The concentration of HrpZ solution was adjusted to avoid protein denaturing when PFLP intensified the acute response of HR necrosis (22). Thus, each purified protein was mixed with $\mathrm{HrpZ}$ at $0.3 \mu \mathrm{g} / \mathrm{ml}$ of the final concentration and infiltrated into the leaves of Col-0. Protein was extracted from the leaves after $1 \mathrm{~h}$ infiltration using an extraction buffer $(100 \mathrm{mM} \mathrm{NaCl}, 50 \mathrm{mM}$ Tris- $\mathrm{HCl}$, and $1 \mathrm{mM}$ PMSF at pH 7.5) containing $1 \times$ of PhosSTOP (Roche, Germany) to avoid protein dephosphorylation. Fifty micrograms of total protein extract was fractionated through electrophoresis in $15 \%$ SDS-PAGE and transferred to an Immobilon-P PVDF membrane (Millipore). Western blot testing was performed using $3 \mu \mathrm{g}$ $(1: 2,000)$ of rabbit polyclonal anti-PFLP-P and anti-PFLP-NP antiserums specific to the phosphorylated and total purified protein, respectively (LTK BioLaboratories, Taiwan). The reactions of secondary antibodies and color visualization were performed in accordance with the process described above.

Construction of plasmids for plant transformation. One recombinant plasmid pBI-ESF harboring the es-pflp, which encodes full-length PFLP for extracellular secretion, was constructed in pBI121 (Clontech) (22). To produce two truncated versions derived from es-pflp, DNA fragments were amplified from es-pflp using primers PFLP-ESX-F/PFLP-PECS-R and PFLP-ESXF/PFLP-PDCS-R, respectively (Table 1). The amplified fragments es-pec and $e s-p d c$ were further subcloned in $\mathrm{pBI} 121$ to generate the plasmids pBI-ESFEC and pBI-ESFDC, respectively. These two plasmids were transformed into Agrobacterium tumefaciens GV3101, and the inserted fragments of es-pec and es-pdc were sequenced and compared with the sequences on Genebank.

Generation and molecular characterization of transgenic Arabidopsis. The transformation of the Arabidopsis thaliana ecotype Col-0 was performed using Agrobacterium tumefaciens (5). Transgenic seeds were screened using a rapid screening protocol (12) using 1/2 Murashige and Skoogs medium (1/2 MS) containing kanamycin, whereupon the seedlings were transplanted into pots containing sterilized soil. Over $10 \mathrm{~T}_{1}$ transgenic lines

TABLE 1. Primers used in this study

\begin{tabular}{ll}
\hline Primer & \multicolumn{1}{c}{ Sequence } \\
\hline PFLP-N16F & 5'-TCCGCATATGGCTTCATACAAAGTG-3' \\
PFLP-B16RM & 5'-GAGAGGATCCTTAGCCCACGAG-3' \\
PEC-B16R & 5'-CAGCCGGATCCTTATTCTTTG-3' \\
PDC-B16R & 5'-CTTCGGATCCTTACTCAATAGTAAC-3' \\
PFLP-ESX-F & 5'-TCTAGAAACCATGTCTCTTAGCCAGAAC-3' \\
PFLP-PECS-R & 5'-ACGAGCTCTCACTCTTTG-3' \\
PFLP-PDCS-R & 5'-CTGAGCTCAAACATCAG-3' \\
LS-ap1-RTF & 5'-CACACCTGACGGACCAAT-3' \\
LS-ap1-RTR2 & 5'-CAGACTGTGGATAAGCAAC-3' \\
\hline
\end{tabular}

A

1 MASYKVKLITPDGPIEFDCPDDVYILDQAEEAGHDLPYSCRAGSCSSCAG 50 51 KIAGGAVDQTDGNFLDDDQLEEGWVLTCVAYPQSDVTIETHKEAELCG 98* $1 \boldsymbol{1}$ PDC PEC

B

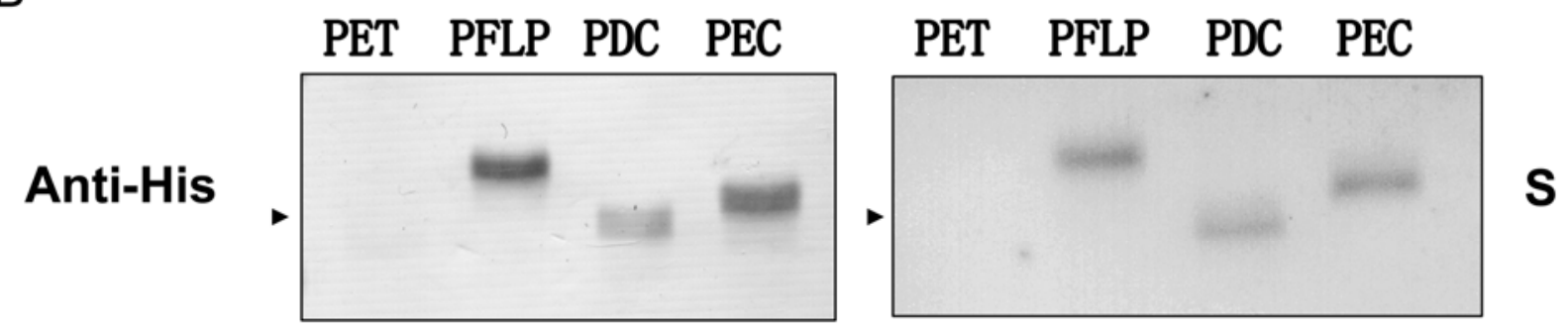

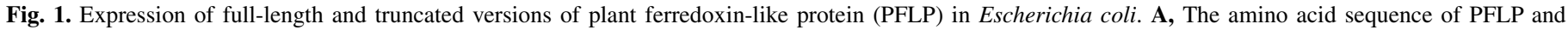

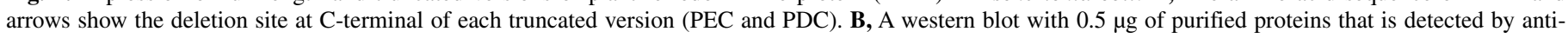
histidine antibody (Anti-His) and stained by Ponceau S staining (S). Arrows indicate the protein size at $17 \mathrm{kDa}$. 
were selected using polymerase chain reaction (PCR). The generation of $T_{2}$ and $T_{3}$ plants for each line was performed through self-pollination, followed by collection of the seeds. Over $100 \mathrm{~T}_{3}$ transgenic plants were identified with PCR to determine whether the $\mathrm{T}_{2}$ transgenic plant was a homozygous line. Two homozygous lines of $\mathrm{T}_{2}$ plants were selected, and their seeds were prepared to generate $\mathrm{T}_{3}$ plants for the succeeding experiments.

Total RNA was isolated from fresh leaf tissue of 4-week-old Arabidopsis plants. The first-strand of cDNA was synthesized using first-strand cDNA synthesis kit for RT-PCR [AMV] (Roche, Germany) from $1 \mu \mathrm{g}$ of total RNA. Then, $200 \mathrm{ng}$ of cDNA was subjected to PCR with primers LS-ap1-RTF (22) and LS-ap1RTR2 (Table 1). The tubulin gene served as a positive control using primers Tub2AF and Tub2AR (20).

For western blot analysis, total protein was extracted from 4-week-old leaf tissue using extraction buffer as described above. Three micrograms of protein extract was fractionated and transferred for immunoblotting. The anti-PFLP antiserum was used as a primary antibody $(1: 2,000)(15)$, and an HRP-conjugated goat anti-rabbit IgG (Rockland) was used as a secondary antibody. The relative quantity of protein compared with nontransgenic Col-0 plant was calculated using AlphaEase FC StandAlone software (Alpha Innotech).

Assessment of disease severity. The disease index was evaluated using the protocol described previously (22). Four-week-old Arabidopsis plants were grown in a growth chamber at $25^{\circ} \mathrm{C}$ to assess the severity of disease according to bacterial wilt. The disease index of Arabidopsis plants challenged with $R$. solanacearum $\mathrm{Rd} 15$ was calculated every 2 weeks postinoculation. The scale of wilting symptoms spanned from 0 to $6(0$, no wilting; 1 , one to two leaves wilting; 2 , three to four leaves wilting; 3, five to six leaves wilting; 4, seven to eight leaves wilting; 5, over nine leaves wilting; and 6, death) was scored for the total number $(\mathrm{N})$ of plants. The disease index for each trial was calculated using the following formula: $\left[\left(0 \times \mathrm{N}_{0}+1 \times \mathrm{N}_{1}+\right.\right.$ $\left.\left.2 \times \mathrm{N}_{2}+3 \times \mathrm{N}_{3}+4 \times \mathrm{N}_{4}+5 \times \mathrm{N}_{5}+6 \times \mathrm{N}_{6}\right) /(6 \times \mathrm{N})\right] \times 100 \%$ (37). This assay tested 12 Arabidopsis plants for replicates.

Expression of Atrboh genes in transgenic plants. To determine whether transgenic plants with truncated versions of PFLP influenced the expression levels of Atrboh genes during harpinmediated HR, 4-week-old transgenic plants were infiltrated with $\mathrm{HrpZ}$ at $0.5 \mathrm{mg} / \mathrm{ml}$. At 0 and $24 \mathrm{~h}$ postinfiltration, first-strand cDNA was prepared and amplified with specific primers (22). The intensity of PCR products in $1.5 \%$ agarose gel of Atrboh genes was compared with that of the tubulin gene using AlphaEase FC StandAlone software (Alpha Innotech). The relative expression level was normalized by the mean of Col- 0 at $0 \mathrm{~h}$.

\section{RESULTS}

Full-length and truncated versions of PFLP on harpinmediated HR. To generate the truncated versions of PFLP, DNA fragments were constructed and expressed in E. coli. The PEC had five amino acids (from residue 94 to 98 ) deleted to reveal or uncover the CK2P site, while the PDC had nine amino acids (from residue 90 to 98) deleted to remove CK2P site (Fig. 1A). Purified PFLP and its truncated versions were detected using Anti-6x-His rabbit polyclonal antiserum with distinct sizes in SDS-PAGE (Fig. 1B).

The recombinant protein of PFLP purified from E. coli intensifies harpin-mediated HR (6). During this response, harpinactivated kinase phosphorylates the PFLP in the tobacco plants

A PFLP

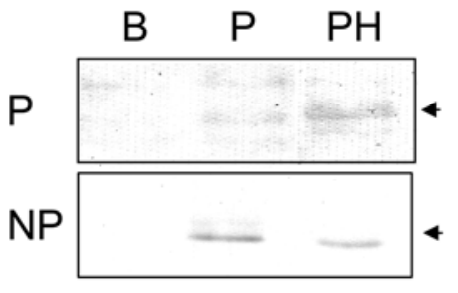

D

B PEC
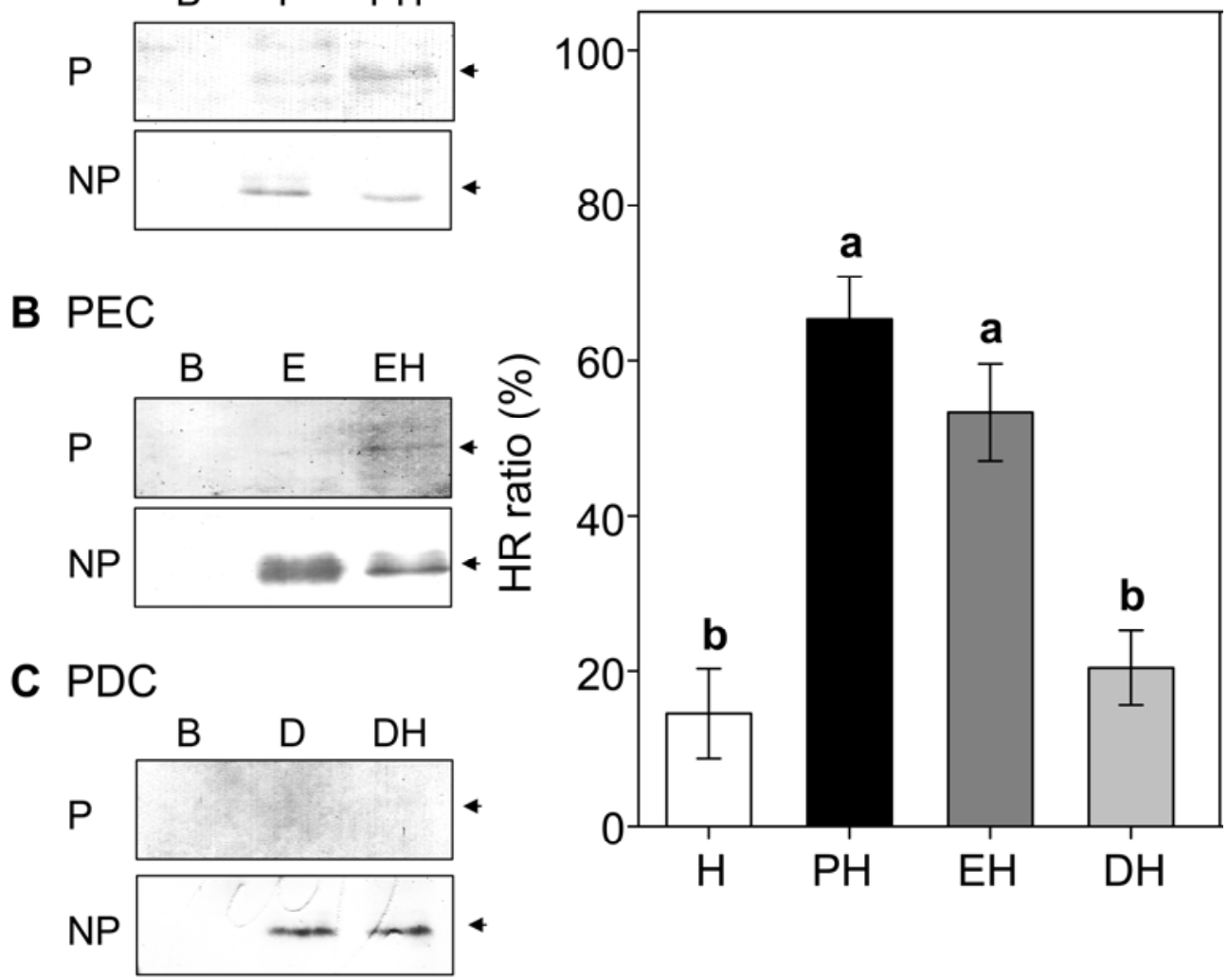

Fig. 2. Phosphorylation and hypersensitive response (HR) assay of purified proteins in Arabidopsis thaliana Col-0 plants. Each purified protein (B, blank; $\mathrm{P}$, plant ferredoxin-like protein [PFLP]; E, PEC; and D, PDC) was mixed with HrpZ (H) at a final concentration of $0.3 \mathrm{mg} / \mathrm{ml}$ to obtain their mixtures (PH, EH, and DH). The mixtures were infiltrated into the leaves, and samples were collected and extracted at $1 \mathrm{~h}$ postinfiltration. A to C, Purified proteins (A, PFLP; B, PEC; and C, PDC) were detected by anti-PFLP-P antiserum (P) or anti-PFLP-NP antiserum (NP) to detect the phosphorylated or total purified proteins, respectively. D, HR ratios induced by distinct mixtures at $24 \mathrm{~h}$ after infiltration, respectively. Letters indicate significant differences based on Duncan's multiple range test $(P<0.05)$. 
(14). To determine how the CK2P site of PFLP contributes to the enhancement of this HR, purified proteins were co-infiltrated with harpin in Arabidopsis Col-0 plant, whereupon the phosphorylation signal was checked. Blotting images using antiserum specific to phosphorylated PFLP (anti-PFLP-P) revealed the immunosignals of phosphorylated proteins, while the total purified proteins were detected using antiserum specific to PFLP (anti-PFLPNP) as a control. Treatment without PFLP or its truncated versions revealed no signal in the leaf extract, indicating that the antiserums were specific to PFLP (Fig. 2). In the treatment involving full-length PFLP, the PFLP with HrpZ produced a stronger phosphorylated signal than the sample without HrpZ did (Fig. 2A). In addition, during the treatment with PEC, the PEC with HrpZ showed a phosphorylated signal, whereas in PEC without HrpZ disappeared (Fig. 2B). For PDC, no phosphorylated signals were detected with or without HrpZ (Fig. 2C). These results demonstrate that the $\mathrm{CK} 2 \mathrm{P}$ site of PFLP is necessary for phosphorylation in response to HrpZ.

To determine whether the PFLP or its truncated versions intensify harpin-mediated HR, purified proteins were co-infiltrated with HrpZ in Col-0 plants to evaluate the ratio of harpin-mediated HR. Because the HrpZ solution at $0.5 \mathrm{mg} / \mathrm{ml}$ did not induce HR necrosis in all of the inoculation sites on Arabidopsis Col-0 plants, the ratio of HR was calculated by counting the number of inoculation sites with necrosis and dividing this by six inoculation sites in one plant, at $24 \mathrm{~h}$ postinfiltration. The HR ratio on Col-0 plants initially induced by HrpZ was $14.5 \%$. When HrpZ was added, the ratio with PFLP or PEC increased to 65.4 and $53.3 \%$, respectively. However, PDC with HrpZ was similar to that of HrpZ alone (Fig. 2D). These results indicate that the full-length PFLP and PEC can be phosphorylated and its harpin-mediated HR intensified, while PDC cannot.

Molecular characterization of transgenic lines. To estimate the actual contribution of the CK2P site of PFLP to the enhancement of disease resistance in transgenic plants, DNA fragments harboring two truncated versions of PFLP were constructed in the plasmid pBI121. The plasmid pBI-ESPEC contained the es-pec, encoding PEC for extracellular secretion, and pBI-ESPDC contained $e s-p d$, encoding PDC for extracellular secretion (Fig. 3A). Transgenic Arabidopsis plants, secreting extracellular PEC (ESFEC) and PDC (ESFDC), were generated with no apparent morphological differences between transgenic and nontransgenic Col-0 plants (data not shown). Two homozygous lines of each transgenic Arabidopsis plant were selected for further experiments. All lines of ESFEC (line 2-4 and line 3-2) and ESFDC (line 6-2 and line 7-5) $\mathrm{T}_{3}$ transgenic plants showed the presence of

A pBI-ESPFLP
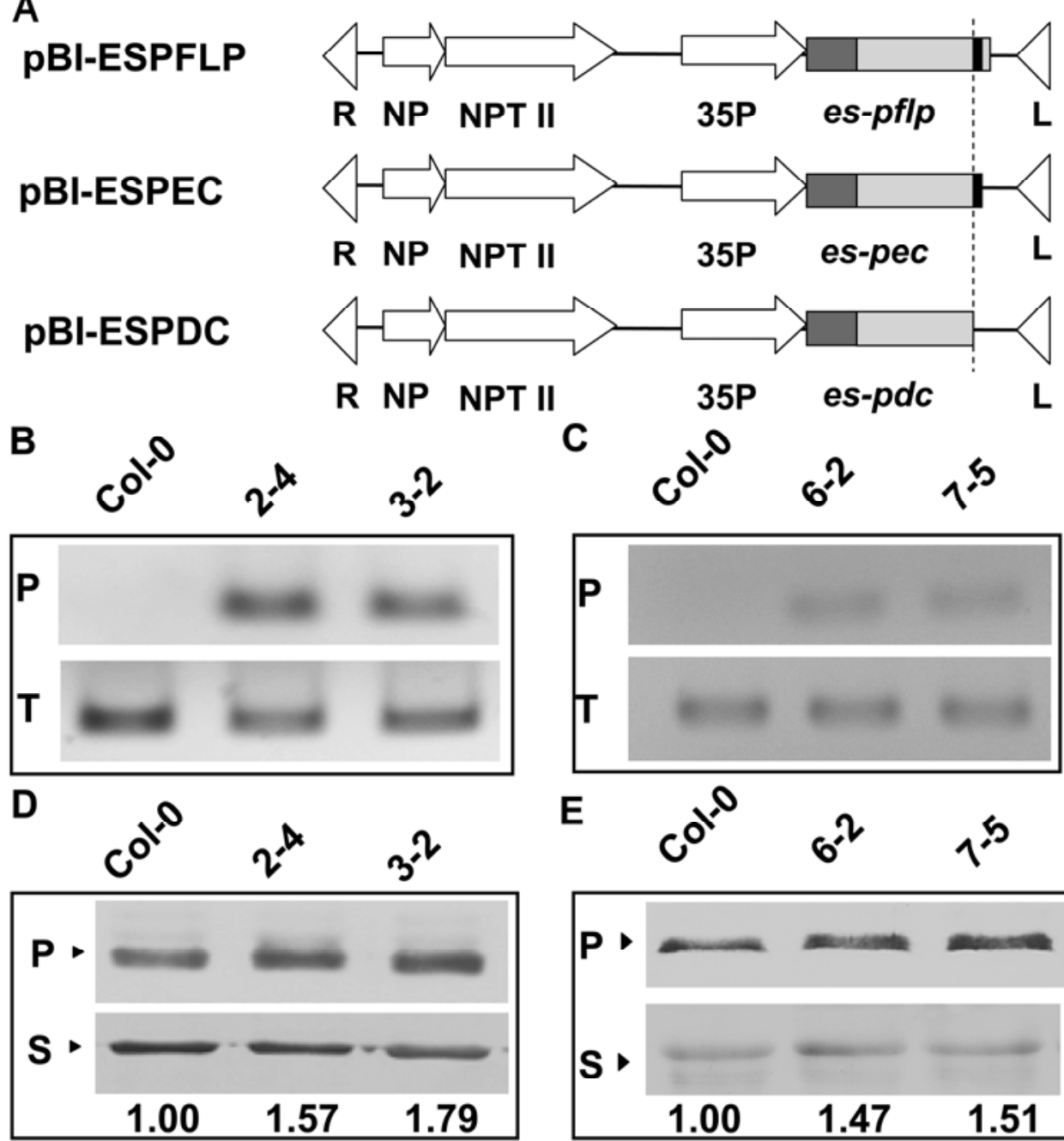

E
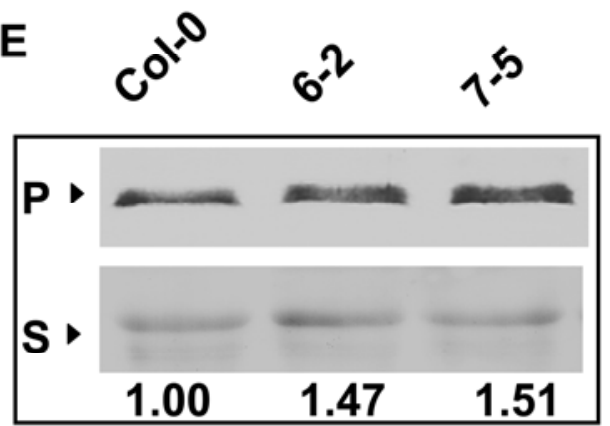

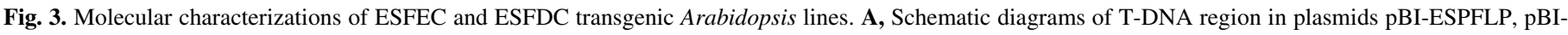

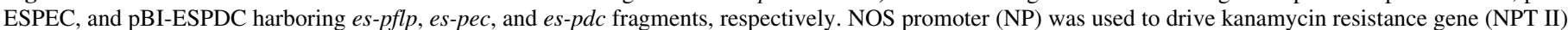

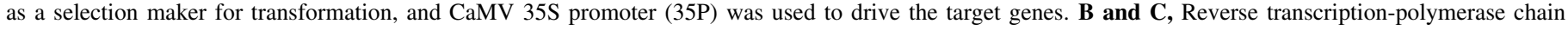

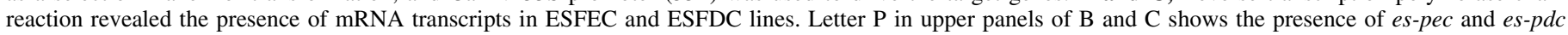

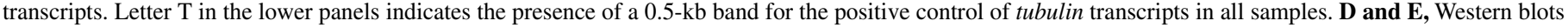

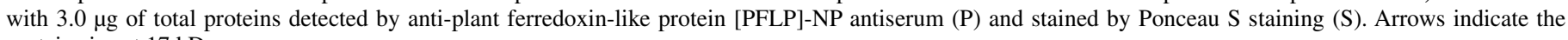
protein size at $17 \mathrm{kDa}$. 
es-pec or es-pdc transcripts by RT-PCR, respectively (Fig. 3B and C). Neither recombinant DNA of PFLP nor transcripts of its truncated versions appeared in nontransgenic Col-0 plants. The protein expression levels of $\mathrm{T}_{3}$ transgenic plants and Col-0 plants were examined using anti-PFLP antiserum in western blot analysis. The endogenous ferredoxin at $17 \mathrm{kDa}$ was visualized in Col-0 and all transgenic plants, but their intensities varied. Compared with the signal in Col-0 plants (as 1.00), the signal intensity increased 1.57-fold in ESFEC line 2-4, 1.79-fold in ESFEC line 3-2, 1.47-fold in ESFDC line 6-2, and 1.51-fold in ESFDC line 7-5 (Fig. 3D and E). These results indicate that the transgenic Arabidopsis plants expressed the transgenes at the protein level in $\mathrm{T}_{3}$ plants.

Harpin-mediated $\mathrm{HR}$ in Arabidopsis plants. Because the CK2P site is required for PFLP to intensify harpin-mediated HR, its effect could be confirmed by evaluating the degree of harpinmediated HR in transgenic plants. The infiltration of HrpZ in Col0 plants did not induce significant $\mathrm{H}_{2} \mathrm{O}_{2}$ generation or $\mathrm{HR}$ necrosis (Fig. 4). ESF 1-19, which is another homozygous line capable of expressing the full length of PFLP for extracellular secretion, was also used as a positive control (22). The accumulation of $\mathrm{H}_{2} \mathrm{O}_{2}$, which appeared in dark brown precipitate, was displayed in the leaves of ESF 1-19 and ESFEC plants. However, ESFDC plants showed no obvious $\mathrm{H}_{2} \mathrm{O}_{2}$ accumulation at $16 \mathrm{~h}$ postinfiltration (Fig. 4A). The ratios of HR in ESF 119 plants were $67.5 \%$, whereas the ESFEC lines were 61.8 and 59.3\%. These plants exhibited higher HR ratios than ESFDC (18.6 and $15.2 \%$ ) and Col-0 plants (15.2\%) (Fig. 4B). These results indicate that transgenic plants expressing PFLP with CK2P site have intensified harpin-mediated HR.

Bacterial wilt disease on Arabidopsis plants. Transgenic plants harboring PFLP confer resistance to bacterial pathogens. To verify whether transgenic plants with truncated versions of
PFLP confer resistance to bacterial pathogens, transgenic plants in this study were challenged with $R$. solanacearum $\mathrm{Rd} 15$. A lower disease index means the plants have greater disease resistance. The disease indexes of ESF 1-19 and ESFEC plants were lower than that of Col-0 (32.4\%) at 2 weeks postinoculation (wpi) (Fig. 5A). The disease indexes of ESF 1-19 and ESFEC plants were approximately half (38.5 to $55.3 \%$ ) those in Col-0 plants $(95.2 \%)$ at 4 wpi. Wilting symptoms in the transgenic plants with PFLP or PEC indicated that they remained resistant to the challenge by Rd15. The degree to which PEC enhanced disease resistance by did not reach that of PFLP (Fig. 5B); however, two lines of ESFDC plants did not decrease their disease indexes (91.6 and 91.7\%) at 4 wpi (Fig. 5A). These results demonstrate that PFLP requires the CK2P site to enhance disease resistance against pathogens causing bacterial wilt.

Expression of AtrbohD and AtrbohF genes during harpinmediated HR. PFLP-enhanced disease resistance and the intensification of harpin-mediated HR were consistent in this study. The level of HR enhancement achieved by PFLP is associated with the expression of the AtrbohD gene (22). Both AtrbohD and AtrbohF play a major role in the production of ROS, triggering HR following interaction with a pathogenic infection $(32,33)$. For this reason, we monitored the expression of AtrbohD and AtrbohF genes in Arabidopsis plants in this study. The ESF 1-19 and ESFEC plants exhibited higher levels of the AtrbohD gene at $24 \mathrm{~h}$ postinfiltration (Fig. 6); while the ESFDC plants showed almost no enhancement in the AtrbohD gene (Fig. 6). All of the transgenic plants exhibited similar expression levels of AtrbohF gene when compared with Col-0 plants (Fig. 6). These results indicate that the CK2P site is required to induce the expression of the AtrbohD gene and trigger HR.

Harpin-mediated HR in Atrboh mutants. Because PFLP with the CK2P site is associated with the expression of the AtrbohD

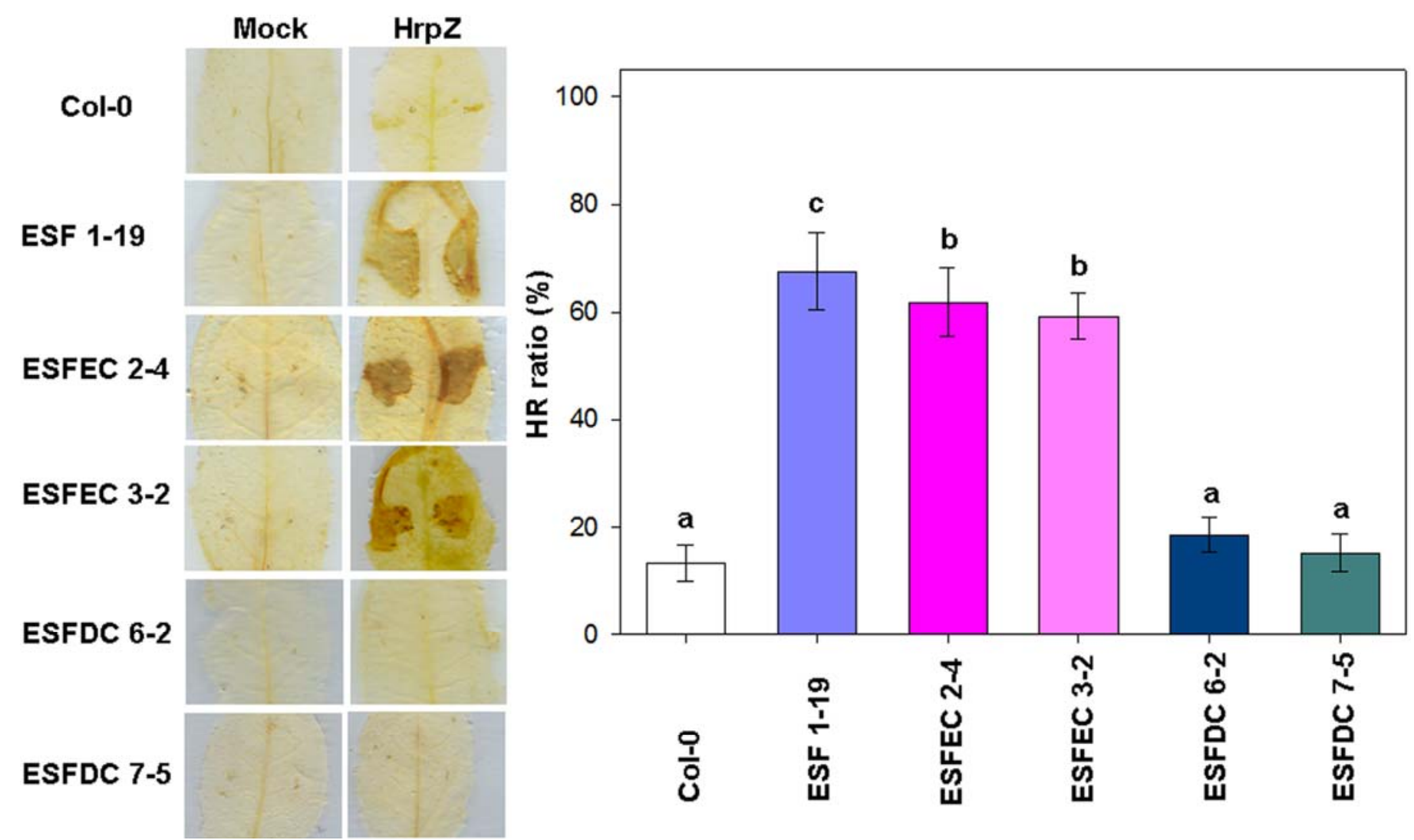

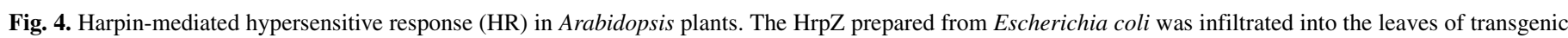

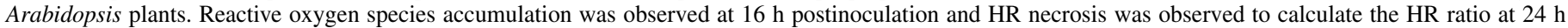

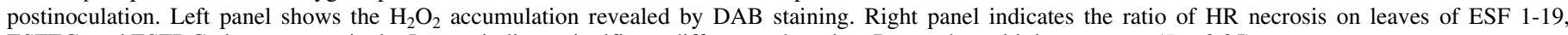
ESFEC, and ESFDC plants, respectively. Letters indicate significant differences based on Duncan's multiple range test $(P<0.05)$ 
gene in Arabidopsis plants, harpin-mediated HR in Arabidopsis plants with Atrboh mutated genes could be used to confirm their influence on HR. Figure 7 shows that the full-length PFLP intensified the ratios of harpin-mediated $\mathrm{HR}$ in nontransgenic Col-0 plants. This effect decreased in AtrbohF mutants and disappeared in AtrbohD and AtrbohD/F double mutants. Treatment with PEC had a similar effect on all of the plants; however, treatment with PDC did not intensify the HR in any plants. These results indicate that the AtrbohD mutant eliminates the majority of harpin-mediated HR.

\section{DISCUSSION}

PFLP mediated-disease resistance can protect plants against a broad range of bacterial diseases through HR. The ratio of HR necrosis induced by harpin in the leaves of transgenic Arabidopsis plants acted as an index describing disease resistance $(13,16,22)$.
Previous research has suggested that sustained resistance to disease can be achieved by apoplastic PFLP through the replacement of the N-terminal signal peptides (22). The $2 \mathrm{Fe}-2 \mathrm{~S}$ domain of PFLP also demonstrates antimicrobial activity inhibiting the growth of bacterial pathogens (15). This study used two truncated versions of PFLP to determine the importance of the CK2P site in intensifying harpin-triggered HR. Purified PEC from E. coli was phosphorylated and found to increase the ratio of harpin-mediated HR; however, PDC did not. The detection of phosphorylated proteins indicates that full-length PFLP can be phosphorylated rapidly, and this phosphorylation requires the CK2P site. This implies that the CK2P site is necessary for the phosphorylation of PFLP to increase the intensity of harpin-mediated HR. The CK2P site is phosphorylated by a casein kinase II (CK2), and this phosphorylation regulates physiological pathways in plants $(19,27,29)$. However, induction of innate immune responses related to CK2 has only been discussed in animal systems (4). The mitogen-

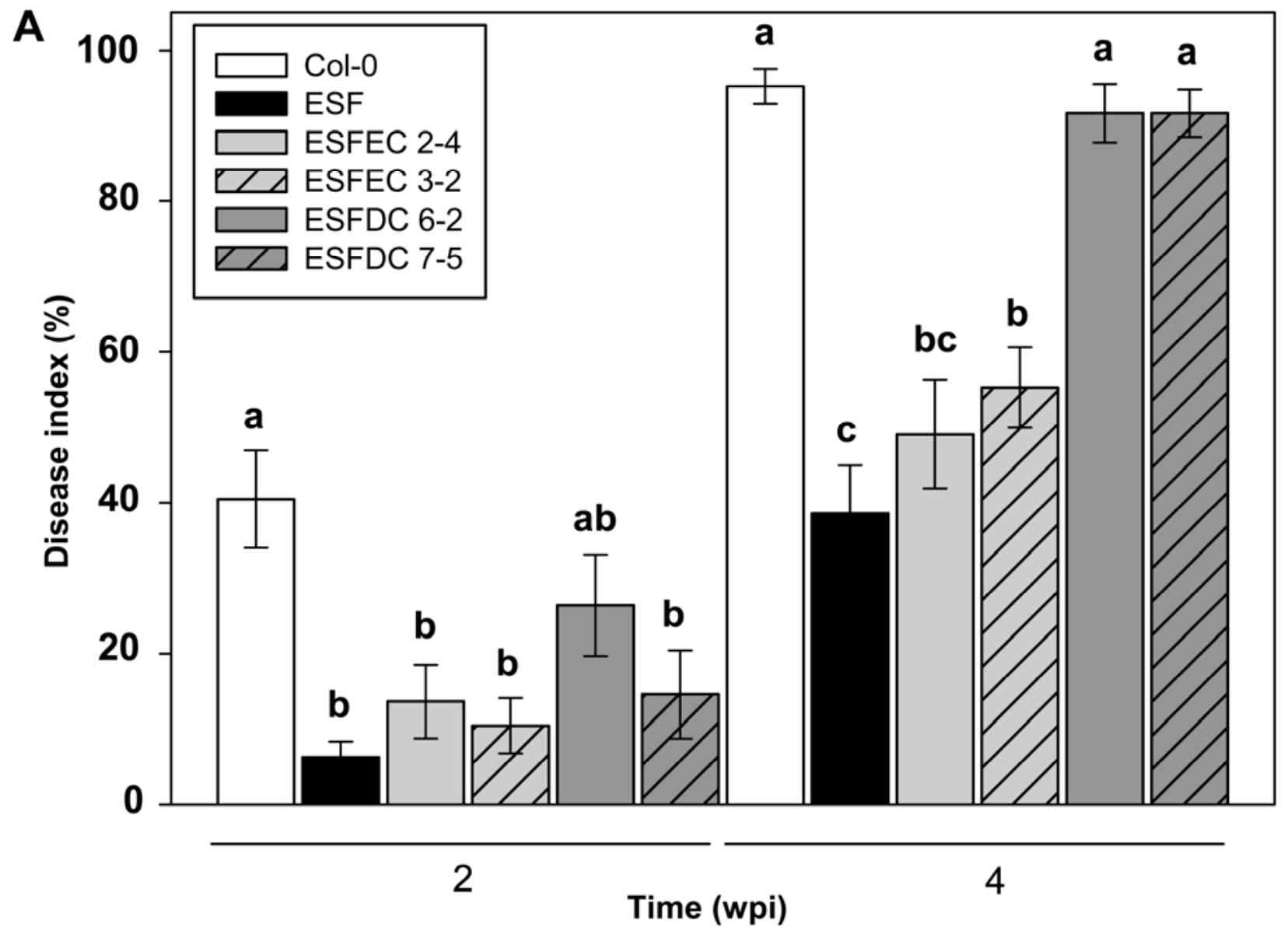

B

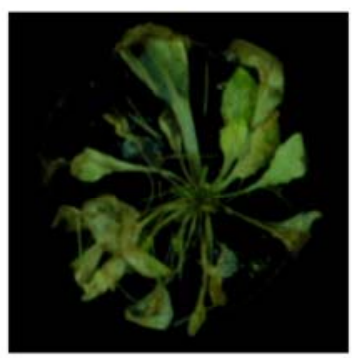

Col-0

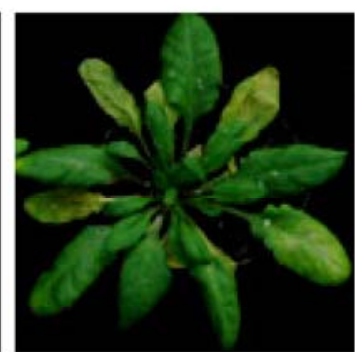

ESF

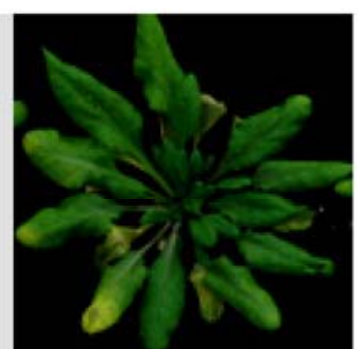

ESFEC

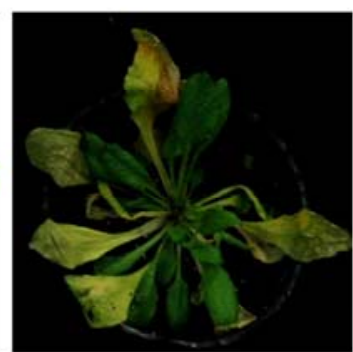

ESFDC

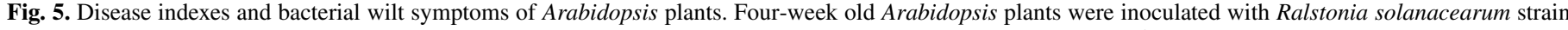

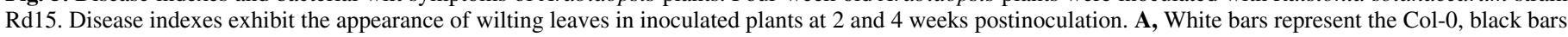

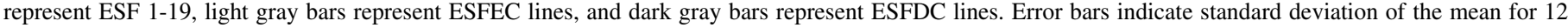

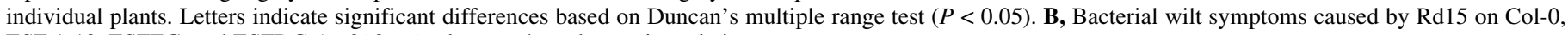
ESF 1-19, ESFEC, and ESFDC Arabidopsis plants at 4 weeks postinoculation. 
associated protein kinase cascade is a key pathway in plant immunity triggered by pathogen-associated molecular patterns $(1,2)$. Evidence has shown that the phosphorylation of CK2P site in the PFLP is clearly associated with intensified harpin-mediated HR, but the components involved in this reaction remain unknown and worthy of further investigation.
Transgenic Arabidopsis plants ESF, ESFEC, and ESFDC were generated to evaluate the actual contribution of PFLP and its truncated versions on disease resistance. The pflp gene does not exist in nontransgenic Col-0 plants, but we detected a signal at $17 \mathrm{kDa}$ using anti-PFLP antiserum similar to results in previous reports (22). The signal was identified as an endogenous leaf type
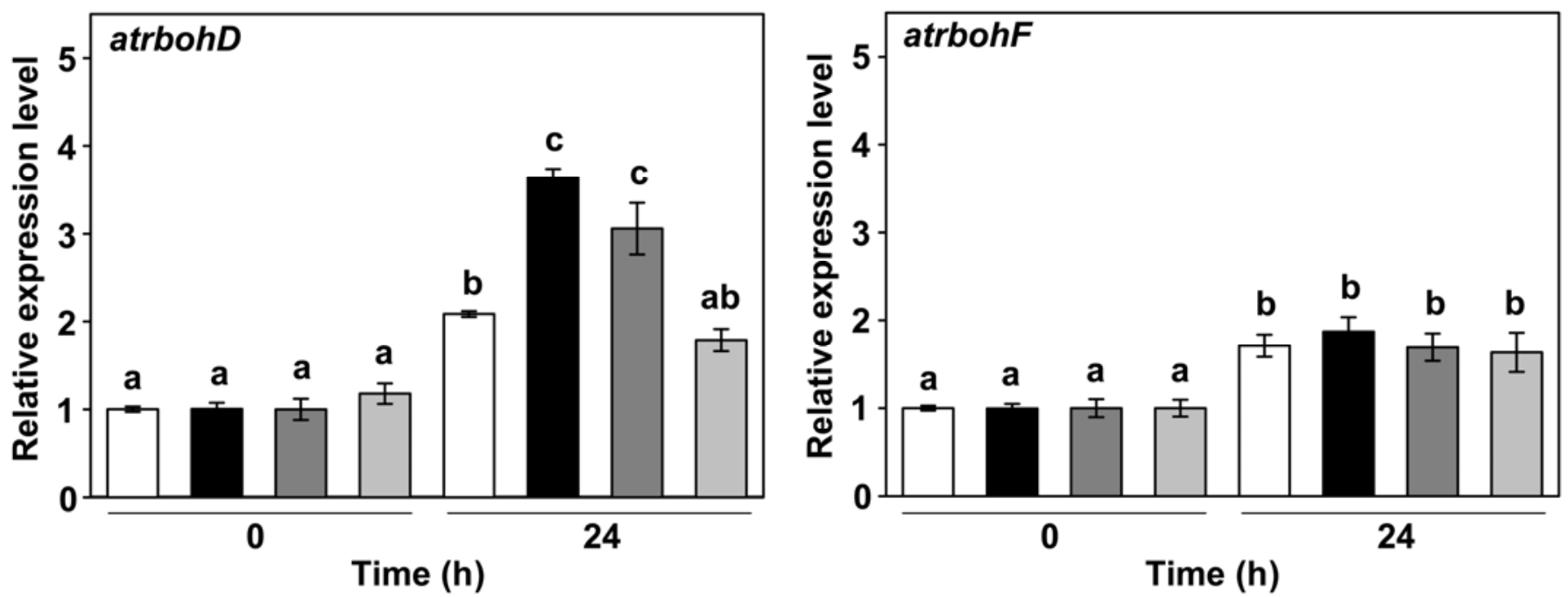

Fig. 6. Relative expression level of Atrboh genes in Arabidopsis plants during harpin-mediated hypersensitive response. The transcripts of Atrboh genes were monitore at 0 and $24 \mathrm{~h}$ after the protein solution of HrpZ was infiltrated into 4-week-old Col-0 (white columns), ESF 1-19 (black columns), ESFEC (dark gray columns), and ESFDC (light gray columns) plants. The relative values of Atrboh transcripts in all of the samples were divided by the mean values of Col-0 at $0 \mathrm{~h}$ to obtain the relative quantity. Each column represents the mean value of six individual leaves postinfiltration. Letters above each column indicate significant differences based on Duncan's multiple range test $(P<0.05)$.

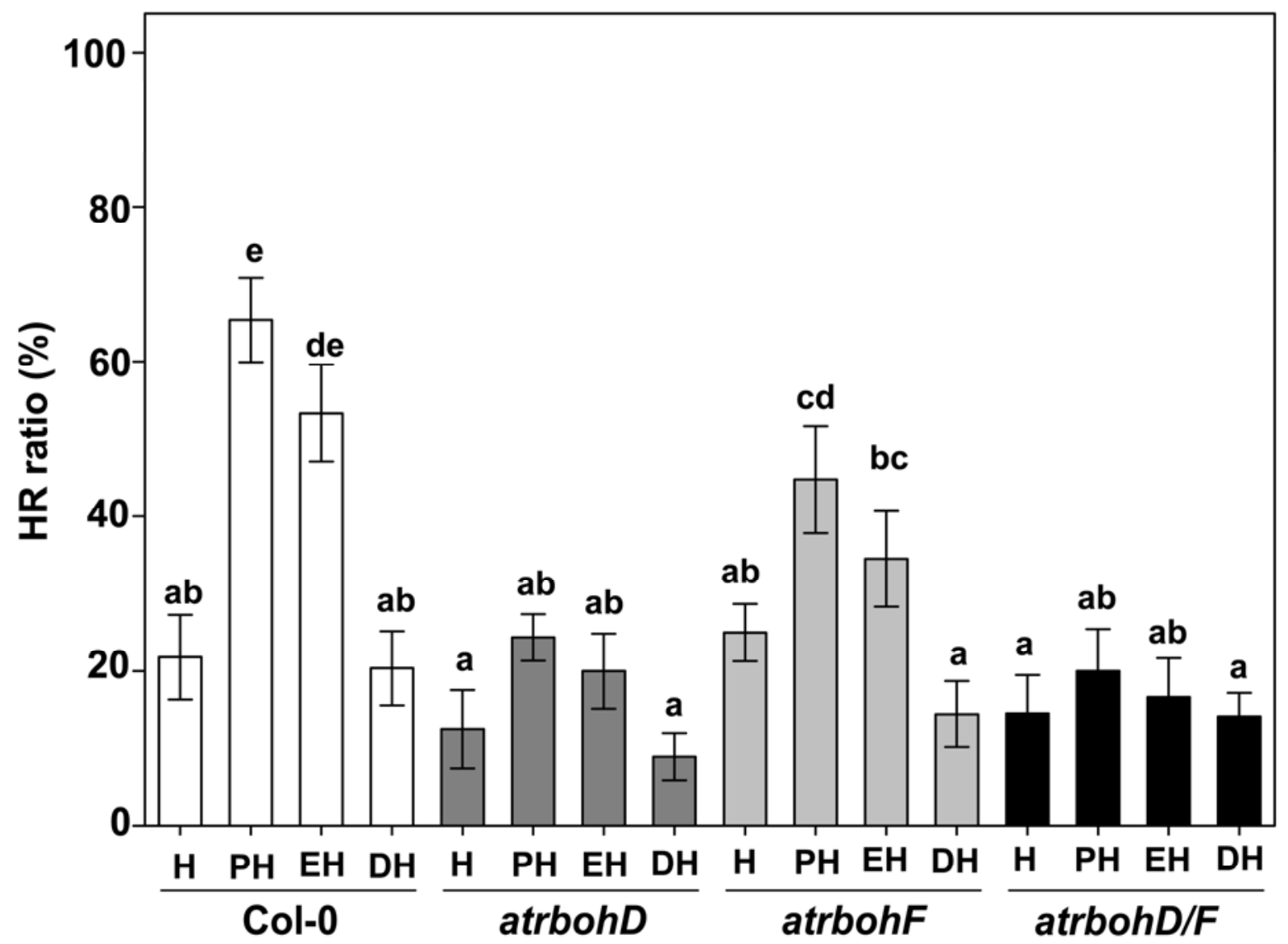

Fig. 7. The harpin-mediated hypersensitive response (HR) in Atrboh mutants. The purified proteins (P, plant ferredoxin-like protein [PFLP]; E, PEC; and D, PDC) were mixed with $\mathrm{HrpZ}(\mathrm{H})$ at the final concentration of $0.5 \mathrm{mg} / \mathrm{ml}(\mathrm{PH}, \mathrm{EH}$, and $\mathrm{DH})$. Each mixture was infiltrated into the leaves of AtrbohD, AtrbohF, and AtrbohD/F double mutants. HR necrosis was observed to calculate the HR ratio at $24 \mathrm{~h}$ postinoculation. Letters indicate significant differences based on Duncan's multiple range test $(P<0.05)$. 
ferredoxins, Atfd2 (Atlg60950) or Atfdl (Atlg10960) (11,35). Our results show that expressed truncated proteins and endogenous ferredoxins extracted from transgenic plants cannot be separated in SDS-PAGE. The anomalous migration in SDS-PAGE of truncated proteins and endogenous ferredoxin is associated with similarities in the tertiary structure and working conditions involved in electrophoresis $(28,36)$. However, a comparison of the intensity of immuno-signals in transgenic and Col-0 plants identified differences of approximately 1.5 - to 1.8 -fold. In addition, mRNA transcripts of engineered transgenes in transgenic plants were made during transcription. Therefore, we propose that the transgenes were expressed at the protein level in transgenic plants, and these transgenic plants could be used for further analysis.

Harpin-mediated $\mathrm{HR}$ is an indicator of disease resistance against bacterial pathogens, and the results of this study show the HR was enhanced in transgenic plants with PFLP and PEC, but not plants with PDC. This suggests that the CK2P site of PFLP in transgenic plants is required to intensify harpin-mediated HR. Transgenic plants were challenged with a bacterial pathogen, $R$. solanacearum, to evaluate their resistance to disease. Results indicate that the enhancement of resistance to disease decreased slightly in ESFEC plants, but this effect disappeared in ESFDC plants. Interestingly, an in vitro study of CK2P with truncated PFLP maintains its antimicrobial activity against a soft-rot pathogen (15). However, our results suggest that the resistance to disease is primarily due to the PFLP-intensified HR pathway rather than antimicrobial activity. In addition, transgenic plants with PEC, an extant CK2P site, also exhibit HR and disease resistance when compared with plants with full-length PFLP. Although harpin treatment can phosphorylate PFLP and PEC, evidence has shown that PFLP is more effective than PEC in enhancing HR and resistance to disease. The efficiency of an engrailed protein phosphorylated by casein kinase II decreases following truncation of its domain (3). The last five amino acids from the C-terminal may regulate the recognition or biochemical activity of PFLP and confer disease resistance. In addition to the nature of PFLP as an electron transfer protein, the redox potential of PFLP and its truncated proteins in plants are also important issues requiring further investigation.

The generation of ROS in plants during an attack of bacterial pathogens is associated with the membrane-bound NADPH oxidase homologues encoded by the rboh genes $(31,40)$. The AtrbohD and AtrbohF genes are essential for the accumulation of ROS in the defense response of Arabidopsis (32). Disease resistance intensified by PFLP is also associated with the AtrbohD gene (22). The expression level of AtrbohD increased by approximately threefold in transgenic plants with PEC compared with the levels in nontransgenic Col-0 plants. However, this increase in intensity did not appear in transgenic plants with PDC. These results indicate that the CK2P site of PFLP is associated with the induction of the AtrbohD gene in transgenic plants. The AtrbohD and AtrbohD/F double mutants eliminated PFLP-intensified HR, indicating that the membrane protein RBOHD must play a role in increasing the intensity of HR. This implies that PFLP phosphorylation and AtrbohD gene induction occurred after the recognition of bacterial elicitors triggering resistance to disease in plants. Similarly, Nbrboh genes in tobacco contribute to the generation of ROS and resistance to Phytophthora infestans (40). The AtrbohD-mediated generation of ROS is also triggered by oligogalacturonide from Arabidopsis, but this reaction is not required to provide resistance against the fungal pathogen Botrytis cinerea (8). Moreover, the RBOHA of barley participates in the penetration of powdery mildew fungus (34). Thus, whether PFLP enhances disease resistance against fungal pathogens is worthy of further investigation. This study demonstrates that the CK2P site of PFLP is required for phosphorylation to further activate the generation of ROS, and this effect is crucial to the enhancement of disease resistance against bacterial pathogens.

\section{ACKNOWLEDGMENTS}

This work was supported by grants to T.-Y. Feng from Academia Sinica, Taiwan. We thank J. L. Dangl, University of North Carolina, for the seeds of Atrboh mutants; M. Angel Torres, Universidad Politécnica de Madrid, for helpful discussion on Atrboh mutants; and C. Malmis for helpful comments on this manuscript.

\section{LITERATURE CITED}

1. Bent, A. F., and Mackey, D. 2007. Elicitors, effectors, and R genes: The new paradigm and a lifetime supply of questions. Annu. Rev. Phytopathol. 45:399-436.

2. Boller, T., and He, S. Y. 2009. Innate immunity in plants: An arms race between pattern recognition receptors in plants and effectors in microbial pathogens. Science 324:742-744.

3. Bourbon, H.-M., Martin-Blanco, E., Rosen, D., and Kornberg, T. B. 1995. Phosphorylation of the Drosophila engrailed protein at a site outside its homeodomain enhances DNA binding. J. Biol. Chem. 270:11130-11139.

4. Chai, L., Dai, L., Che, Y., Xu, J., Liu, G., Zhang, Z., and Yang, R. 2009. LRRC19, a novel member of the leucine-rich repeat protein family, activates NF-kappaB and induces expression of proinflammatory cytokines. Biochem. Biophys. Res. Commun. 388:543-548.

5. Clough, S. J., and Bent, A. F. 1998. Floral dip: A simplified method for Agrobacterium-mediated transformation of Arabidopsis thaliana. Plant $\mathrm{J}$. 16:735-743.

6. Dayakar, B. V., Lin, H.-J., Chen, C.-H., Ger, M.-J., Lee, B.-H., Pai, C.H., Chow, D., Huang, H.-E., Hwang, S.-Y., Chung, M.-C., and Feng, T.Y. 2003. Ferredoxin from sweet pepper (Capsicum annиum L.) intensifying harpin ${ }_{\mathrm{pss}}$-mediated hypersensitive response shows an enhanced production of active oxygen species (AOS). Plant Mol. Biol. 51:913-924.

7. Fryer, M. J., Oxborough, K., Mullineaux, P. M., and Baker, N. R. 2002. Imaging of photo-oxidative stress responses in leaves. J. Exp. Bot. 53:1249-1254.

8. Galletti, R., Denoux, C., Gambetta, S., Dewdney, J., Ausubel, F. M., De Lorenzo, G., and Ferrari, S. 2008. The AtrbohD-mediated oxidative burst elicited by oligogalacturonides in Arabidopsis is dispensable for the activation of defense responses effective against Botrytis cinerea. Plant Physiol. 148:1695-1706.

9. Ger, M.-J., Chen, C.-H., Hwang, S.-Y., Huang, H.-E., Podile, A. R., Dayakar, B. V., and Feng, T.-Y. 2002. Constitutive expression of hrap gene in transgenic tobacco plant enhances resistance against virulent bacterial pathogens by induction of a hypersensitive response. Mol. PlantMicrobe Interact. 15:764-773.

10. Grant, J. J., and Loake, G. J. 2000. Role of reactive oxygen intermediates and cognate redox signaling in disease resistance. Plant Physiol. 124:2129.

11. Hanke, G. T., and Hase, T. 2008. Varible photosynthetic roles of two leaftype ferredoxins in Arabidopsis, as revealed by RNA interference. Photochem. Photobiol. 84:1302-1309.

12. Harrison, S. J., Mott, E. K., Parsley, K., Aspinall, S., Gray, J. C., and Cottage, A. 2006. A rapid and robust method of identifying transformed Arabidopsis thaliana seedlings following floral dip transformation. Plant Methods 2:19.

13. He, S. Y., Huang, H. C., and Collmer, A. 1993. Pseudomonas syringae pv. syringae harpin $\mathrm{Pss}_{\mathrm{Ps}}$ : A protein that is secreted via the Hrp pathway and elicits the hypersensitive response in plant. Cell 73:1255-1266.

14. Huang, H.-E., Ger, M.-J., Chen, C.-Y., Pandey, A.-K., Yip, M.-K., Chou, H.-W., and Feng, T.-Y. 2007. Disease resistance to bacterial pathogens affected by the amount of ferredoxin-I protein in plants. Mol. Plant Pathol. 8:129-137.

15. Huang, H.-E., Ger, M.-J., Chen, C.-Y., Yip, M.-K., Chung, M.-C., and Feng, T.-Y. 2006. Plant ferredoxin-like protein (PFLP) exhibits an antimicrobial ability against soft-rot pathogen Erwinia carotovora subsp. carotovora in vitro and in vivo. Plant Sci. 171:17-23.

16. Huang, H.-E., Ger, M.-J., Yip, M.-K., Chen, C.-Y., Pandeya, A.-K., and Feng, T.-Y. 2004. A hypersensitive response was induced by virulent bacteria in transgenic tobacco plants overexpressing a plant ferredoxinlike protein (PFLP). Physiol. Mol. Plant Pathol. 64:103-110.

17. Huang, H.-E., Liu, C.-A., Lee, M.-J., Kuo, C.-G., Chen, H.-M., Ger, M.-J., Tsai, Y.-C., Chen, Y.-R., Lin, M.-K., and Feng, T.-Y. 2007. Resistance enhancement of transgenic tomato to bacterial pathogens by the heterologous expression of sweet pepper ferredoxin-I protein. Phytopathology 97:900-906.

18. Kelman, A. 1954. The relationship of pathogenicity in Pseudomonas solanacearum to colony appearance on a tetrazolium medium. Phytopathology 44:693-695.

19. Krick, R., Aschrafi, A., Hasgün, D., and Arnemann, J. 2006. CK2- 
dependent $\mathrm{C}$-terminal phosphorylation at $\mathrm{T}^{300}$ directs the nuclear transport of TSPY protein. Biochem. Biophys. Res. Commun. 341:343-350.

20. Lee, H., Suh, S.-S., Park, E., Cho, E., Ahn, J. H., Kim, S.-G., Lee, J. S., Kwon, Y. M., and Lee, I. 2000. The AGAMOUS-LIKE 20 MADS domain protein integrates floral inductive pathways in Arabidopsis. Genes Dev. 14:2366-2376.

21. Liau, C.-H., Lu, J.-C., Prasad, V., Hsiao, H.-H., You, S.-J., Lee, J.-T., Yang, N.-S., Huang, H.-E., Feng, T.-Y., Chen, W.-H., and Chan, M.-T. 2003. The sweet pepper ferredoxin-like protein ( $p f l p)$ conferred resistance against soft rot disease in Oncidium orchid. Transgenic Res. 12:329-336.

22. Lin, Y.-H., Huang, H.-E., Wu, F.-S., Ger, M.-J., Liao, P.-L., Chen, Y.-R., Tzeng, K.-C., and Feng, T.-Y. 2 010. Plant ferredoxin-like protein (PFLP) outside chloroplast in Arabidopsis enhances disease resistance against bacterial pathogens. Plant Sci. 179:450-458

23. Mehdy, M. C. 1994. Active oxygen species in plant defense against pathogens. Plant Physiol. 105:467-472.

24. Mudgett, M. B., and Staskawicz, B. 1998. Protein signaling via type III secretion pathways in phytopathogenic bacteria. Curr. Opin. Microbiol. $1: 109-114$.

25. Mur, L. A. J., Kenton, P., Llord, A., Ougham, H., and Prats, E. 2008. The hypersensitive responses; the centenary is upon us but how much do we know? J. Exp. Bot. 59:501-520.

26. Nicaise, V., Roux, M., and Zipfel, C. 2009. Recent advances in PAMPtriggered immunity against bacteria: Pattern recognition receptors watch over and raise the alarm. Plant Physiol. 150:1638-1647.

27. Ogiso, E., Takahashi, Y., Sasaki, T., Yano, M., and Izawa, T. 2010. The role of casein kinase II in flowering time regulation has diversified during evolution. Plant Physiol. 152:808-820.

28. Rath, A., Glibowicka, M., Nadeau, V. G., Chen, G., and Deber, C. M. 2009. Detergent binding explains anomalous SDS-PAGE migration of membrane proteins. Proc. Natl. Acad. Sci. USA 106:1760-1765.

29. Riera, M., Figueras, M., López, C., Goday, A., and Pagès, M. 2004. Protein kinase CK2 modulates developmental functions of the abscisic acid responsive protein Rab17 from maize. Proc. Natl. Acad. Sci. USA 101:9879-9884.

30. Torres, M. A. 2010. ROS in biotic interactions. Physiol. Plant. 138:414429.
31. Torres, M. A., and Dangl, J. L. 2005. Functions of the respiratory burst oxidase in biotic interactions, abiotic stress and development. Curr. Opin. Plant Biol. 8:397-403.

32. Torres, M. A., Dang, J. L., and Jones, J. D. G. 2002. Arabidopsis gp91 phox homologues AtrbohD and AtrbohF are required for accumulation of reactive oxygen intermediates in the plant defense response. Proc. Natl. Acad. Sci. 99:517-522.

33. Torres, M. A., Jones, J. D. G., and Dangl, J. L. 2005. Pathogen-induced, NADPH oxidase-derived reactive oxygen intermediates suppress spread of cell death in Arabidopsis thaliana. Nat. Genet. 37:1130-1134.

34. Trujillo, M., Altschmied, L., Schweizer, P., Kogel, K.-H., and Hückelhoven, R. 2006. Respiratory Burst Oxidase Homologue A of barley contributes to penetration by the powdery mildew fungus Blumeria graminis f. sp. hordei. J. Exp. Bot. 57:3781-3791

35. Voss, I., Koelmann, M., Wojtera, J., Holtgrefe, S., Kitzmann, C. Backhausen, J. E., and Scheibe, R. 2008. Knockout of major leaf ferredoxin reveals new redox-regulatory adaptations in Arabidopsis thaliana. Physiol. Plant. 133:584-598.

36. Westerhuis, W. H. J., Sturgis, J. N., and Niederman, R. A. 2000. Reevaluation of the electrophoretic migration behavior of soluble globular proteins in the native and detergent-denatured states in polyacrylamide gels. Anal. Biochem. 284:143-152.

37. Winstead, N. N., and Kelman, A. 1952. Inoculation techniques for evaluating resistance to Pseudomonas solanacearum. Phytopathology 42:628-634.

38. Wu, G., Shortt, B. J., Lawrence, E. B., Levine, E. B., Fitzsimmons, K. C., and Shah, D. M. 1995. Disease resistance conferred by expression of a gene encoding $\mathrm{H}_{2} \mathrm{O}_{2}$-generating glucose oxidase in transgenic potato plants. Plant Cell 7:1357-1368.

39. Yip, M.-K., Huang, H.-E., Ger, M.-J., Chiu, S.-H., Tsai, Y.-C., Lin, C.-I., and Feng, T.-Y. 2007. Production of soft rot resistant calla lily by expressing a ferredoxin-like protein gene $(p f l p)$ in transgenic plants. Plant Cell Rep. 26:449-457.

40. Yoshioka, H., Numata, N., Nakajima, K., Katou, S., Kawakita, K., Rowland, O., Jones, J. D. G., and Doke, N. 2003. Nicotiana benthamiana gp9 ${ }^{\text {phox }}$ homologs NbrbohA and NbrbohB participate in $\mathrm{H}_{2} \mathrm{O}_{2}$ accumulation and resistance to Phytophthora infestans. Plant Cell 15:706-718. 